\title{
OPEN Risk of cancer development in patients with keloids
}

\author{
Ying-Yi Lu $u^{1,2,3}$, Hung-Pin Tu ${ }^{4,10}$, Chieh-Hsin Wu ${ }^{5,6}$, Chien-Hui Hong ${ }^{1,7}$, Kuo-Chia Yang ${ }^{8}$, \\ Hui-Ju Yang ${ }^{8,12 \bowtie}$, Kee-Lung Chang ${ }^{2,9,10 \bowtie} \&$ Chih-Hung Lee ${ }^{11 \bowtie}$
}

Keloid is a skin disease characterized by exaggerated scar formation, excessive fibroblast proliferation, and excessive collagen deposition. Cancers commonly arise from a fibrotic microenvironment; e.g., hepatoma arises from liver cirrhosis, and oral cancers arise from submucosal fibrosis. As keloids are a prototypic fibroproliferative disease, this study investigated whether patients with keloids have an increased cancer risk. In a matched, population-based study, first 17,401 patients treated for keloids during 1998-2010 with 69,604 controls without keloids at a ratio of 1:4 were evaluated. The association between keloids and risk of cancer was estimated by logistic regression or Cox proportional hazard regression models after adjustment of covariates. In total, 893 first-time cases of cancer were identified in the 17,401 patients with keloids. The overall cancer risk was 1.49fold higher in the keloids group compared to controls. Regarding specific cancers, the keloids group, had a significantly higher risk of skin cancer compared to controls (Relative risk $=1.73$ ). The relative risk for skin cancer was even higher for males with keloids (Relative risk $=2.16$ ). Further stratified analyses also revealed a significantly higher risk of developing pancreatic cancer in female patients with keloids compared to controls (Relative risk $=2.19$ ) after adjustment for known pancreatic cancer risk factors. This study indicates that patients with keloids have a higher than normal risk for several cancer types, especially skin cancers (both genders) and pancreatic cancer (females). Therefore, patients with keloids should undergo regular skin examinations, and females with keloids should regularly undergo abdominal ultrasonography.

Keloids are benign dermal fibro-proliferative tumors characterized by overproliferation of fibroblasts and excessive accumulation of collagen ${ }^{1}$. Keloids are triggered by cutaneous injury followed by abnormal wound recovery ${ }^{2}$. They often invade neighboring normal skin without regression ${ }^{3}$. They often cause intense itching and pain and usually recur after various treatments. Dark-skinned individuals are more susceptible to keloids compared to light-skinned individuals ${ }^{4}$. The exact etiology of keloids remains unclear but is apparently multifactorial. Genetic and environmental factors are often implicated ${ }^{5,6}$.

Cancer is the main cause of mortality worldwide. Uncontrolled fibrocyte proliferation and collagen deposition in keloids are analogous to uncontrolled cell growth and proliferation in cancers. Furthermore, many cancers develop from sclerotic and fibrous microenvironments, e.g., hepatoma develops from liver cirrhosis, oral cancer develops from submucosal fibrosis, and Majorlin's cancer develops from burn scars. Since keloids are a prototypic fibrous proliferative and sclerotic disease of the skin, this study investigated whether patients with keloids have a higher than normal tendency to develop cancers, including skin and internal cancers. Notably, sporadic case reports show that keloids may be a paraneoplastic phenomenon ${ }^{7-9}$. Coppa et al. reported a 66-year-old woman

\footnotetext{
${ }^{1}$ Department of Dermatology, Kaohsiung Veterans General Hospital, Kaohsiung, Taiwan. ${ }^{2}$ Graduate Institute of Medicine, College of Medicine, Kaohsiung Medical University, No. 100, Shih-Chuan 1st Road, Kaohsiung 80708, Taiwan. ${ }^{3}$ Shu-Zen Junior College of Medicine and Management, Kaohsiung, Taiwan. ${ }^{4}$ Department of Public Health and Environmental Medicine, School of Medicine, College of Medicine, Kaohsiung Medical University, Kaohsiung, Taiwan. ${ }^{5}$ Division of Neurosurgery, Department of Surgery, Kaohsiung Medical University Hospital, Kaohsiung, Taiwan. ${ }^{6}$ Department of Surgery, School of Medicine, College of Medicine, Kaohsiung Medical University, Kaohsiung, Taiwan. ${ }^{7}$ Department of Dermatology, Faculty of Medicine, National Yang Ming Chiao Tung University, Taipei, Taiwan. ${ }^{8}$ Departments of Dermatology, Changhua Christian Hospital, No. 135, Nanxiao St., Changhua City, Changhua County 500054, Taiwan. ${ }^{9}$ Department of Biochemistry, School of Medicine, College of Medicine, Kaohsiung Medical University, Kaohsiung, Taiwan. ${ }^{10}$ Department of Medical Research, Kaohsiung Medical University Hospital, Kaohsiung, Taiwan. ${ }^{11}$ Department of Dermatology, Kaohsiung Chang Gung Memorial Hospital and Chang Gung University College of Medicine, No. 123, Ta Pei Rd., Niaosong Dist., Kaohsiung 833, Taiwan. ${ }^{12}$ Institute of Medicine, Chung Shan Medical University, Taichung, Taiwan. ${ }^{\square}$ email: 149777@cch.org.tw; keeluch@kmu.edu.tw; dermlee@gmail.com
} 


\begin{tabular}{|l|l|l|l|}
\hline \multirow{4}{*}{ Variables } & \multicolumn{2}{|l|}{ Keloids } & \multirow{2}{*}{} \\
\cline { 2 - 3 } & Yes & No & \multirow{2}{*}{ P value } \\
\cline { 2 - 3 } & $\mathbf{N}=\mathbf{1 7 , 4 0 1}$ & $\mathbf{N}=\mathbf{6 9 , 6 0 4}$ & $<0.0001$ \\
\hline Cancer, n (\%) & $893(5.13)$ & $2434(3.50)$ & \multicolumn{2}{|l}{} \\
\hline Age mean (SD) (years) & $38.4(14.4)$ & $38.4(14.3)$ & 0.7993 \\
\hline Age group, n (\%) & $11,321(65.1)$ & $45,273(65.0)$ & \\
\hline $20-40$ & $4472(25.7)$ & $18,112(26.0)$ & \\
\hline $41-60$ & $1608(9.2)$ & $6219(8.9)$ & 0.3669 \\
\hline$>60$ & \multicolumn{3}{|l}{} \\
\hline Gender & $6635(38.1)$ & $26,540(38.1)$ & \\
\hline Males & $10,766(61.9)$ & $43,064(61.9)$ & 1.0000 \\
\hline Females & \multicolumn{3}{|l}{} \\
\hline Region, n (\%) & $7511(43.2)$ & $29,660(42.6)$ & \\
\hline Northern & $4759(27.3)$ & $19,156(27.5)$ & \\
\hline Central & $4553(26.2)$ & $18,215(26.2)$ & \\
\hline Southern & $578(3.3)$ & $2573(3.7)$ & 0.0878 \\
\hline Eastern, Offshore islets, and other & & & \\
\hline
\end{tabular}

Table 1. The demographic characteristics of the keloids group and the control group. SD standard deviation.

\begin{tabular}{|l|l|l|l|l|}
\hline Variables & Keloids & Non-keloids group & OR (95\% CI) & P value \\
\hline Overall cancers & 893 & 2434 & $1.49(1.38-1.61)$ & $<0.0001$ \\
\hline Gender & 332 & 871 & $1.55(1.36-1.77)$ & $<0.0001$ \\
\hline Males & 561 & 1563 & $1.46(1.32-1.61)$ & $<0.0001$ \\
\hline Females
\end{tabular}

Table 2. Total cancer risk in patients with keloids, stratified by gender. OR odd ratio, 95\% CI 95\% confidence interval.

who developed eruptive keloids but was diagnosed with endometrial carcinoma ${ }^{9}$. In He et al., an 81-year-old woman developed right breast cancer and eruptive keloids with severe pruritus over a roughly similar time period $^{7}$. Sakaguchi et al. described the development of bilateral breast cancer in a 72 -year-old woman with extensive keloids on the limbs, presternal area, and bilateral breasts. Notably, her serum level of transforming growth factor- $\beta 1$ (TGF- $\beta 1$ ) was abnormally high ${ }^{8}$.

To date, no large epidemiological studies have investigated whether patients with keloids tend to develop cancers. Therefore, this retrospective study used the Taiwan National Health Insurance Research Database (NHIRD) to perform the first matched study in an Asian population.

\section{Results}

Demographic characteristics of the subjects (Table 1). The analysis included 17,401 patients with keloids and 69,604 controls. The average age (38.4 years), gender distribution (61.9\% female), and geographic distribution of the population were comparable after the adjustment strategy was applied (northern $43.2 \%$, central $27.3 \%$, southern $26.2 \%$, eastern, offshore and other $3.3 \%$ ). Keloids were slightly more common in females (61.9\%) than in males. The majority of patients with keloids developed the disease at age 20-40 years old (65.1\%), followed by $41-60$ years old $(25.7 \%)$ and $>60$ years old $(9.2 \%)$. In total, $893(5.13 \%)$ patients developed cancer out of the 17,401 patients who had keloids but no prior cancers. In contrast, the 69,604 controls without keloids included 2434 patients who developed cancer (3.5\%).

Increased overall cancer risk in patients with keloids (Table 2). To determine whether overall cancer risk was higher than normal in patients with keloids, logistic regression analysis was performed to evaluate the association between keloids and overall cancers. The results showed that, compared to controls, patients with keloids had a significantly higher odd ratio (OR) for developing cancer, which is 1.49 with $95 \%$ confidence interval (CI) 1.38-1.61. Additionally, the cancer risk was increased in both male and female patients with keloids.

OR for specific cancers in patients with keloids (Table 3). After identifying an increased overall cancer risk in patients with keloids, we next investigated what specific cancers are associated with keloids. The analysis showed that, compared to controls, the patients with keloids had an increased association with esophageal cancer $(\mathrm{OR}=1.7)$, colon cancer $(\mathrm{OR}=1.54)$, liver cancer $(\mathrm{OR}=1.59)$, pancreatic cancer $(\mathrm{OR}=2.57)$, melanoma $(\mathrm{OR}=3.4)$, nonmelanoma skin cancers $(\mathrm{OR}=4.35)$, breast cancer $(\mathrm{OR}=1.28)$, prostate cancer $(\mathrm{OR}=1.63)$, kid- 


\begin{tabular}{|l|l|l|l|l|l|l|}
\hline Variables & \multicolumn{2}{l}{ All } & \multicolumn{2}{l|}{ Males } & \multicolumn{2}{l|}{ Females } \\
\hline Cancer & OR $(\mathbf{9 5} \% \mathbf{C I})$ & P value & OR $\mathbf{9 5 \%}$ CI) & P value & OR (95\% CI) & P value \\
\hline Oral cancer & $1.16(0.92-1.46)$ & 0.2162 & $1.19(0.87-1.63)$ & 0.2828 & $1.12(0.79-1.59)$ & 0.5099 \\
\hline Esophageal cancer & $1.70(1.06-2.71)$ & 0.0270 & $1.91(0.90-4.05)$ & 0.0933 & $1.58(0.87-2.87)$ & 0.1340 \\
\hline Stomach cancer & $1.29(0.84-1.97)$ & 0.2443 & $1.39(0.79-2.46)$ & 0.2547 & $1.17(0.62-2.23)$ & 0.6308 \\
\hline Colon cancer & $1.54(1.28-1.86)$ & $<0.0001$ & $1.63(1.24-2.15)$ & 0.0005 & $1.47(1.14-1.90)$ & 0.0027 \\
\hline Liver cancer & $1.59(1.30-1.95)$ & $<0.0001$ & $1.82(1.37-2.43)$ & $<0.0001$ & $1.40(1.05-1.87)$ & 0.0212 \\
\hline Pancreatic cancer & $2.57(1.59-4.18)$ & 0.0001 & $2.20(1.05-4.60)$ & 0.0356 & $2.91(1.53-5.55)$ & 0.0011 \\
\hline Lung cancer & $1.12(0.85-1.46)$ & 0.4274 & $1.06(0.73-1.54)$ & 0.7564 & $1.18(0.80-1.74)$ & 0.4061 \\
\hline Melanoma & $3.40(1.78-6.50)$ & 0.0002 & $3.20(1.26-8.12)$ & 0.0142 & $3.60(1.46-8.87)$ & 0.0053 \\
\hline Skin cancer & $4.35(3.16-5.99)$ & $<0.0001$ & $5.89(3.64-9.53)$ & $<0.0001$ & $3.37(2.18-5.22)$ & $<0.0001$ \\
\hline Kaposiss sarcoma & $2.00(0.18-22.06)$ & 0.5714 & $4.00(0.25-63.97)$ & 0.3269 & - & \\
\hline Breast cancer & - & & - & & $1.28(1.03-1.58)$ & 0.0230 \\
\hline Cervical cancer & - & & - & & $1.09(0.78-1.53)$ & 0.5998 \\
\hline Uterine cancer & - & & - & & $1.24(0.78-1.99)$ & 0.3611 \\
\hline Ovarian cancer & - & & - & & $1.32(0.93-1.85)$ & 0.1156 \\
\hline Prostate cancer & - & & $1.63(1.14-2.32)$ & 0.0073 & - & \\
\hline Bladder cancer & $1.16(0.72-1.86)$ & 0.5445 & $1.04(0.57-1.92)$ & 0.8985 & $1.38(0.65-2.96)$ & 0.3999 \\
\hline Kidney cancer & $1.77(1.03-3.03)$ & 0.0386 & $1.69(0.74-3.85)$ & 0.2159 & $1.83(0.90-3.75)$ & 0.0958 \\
\hline Unspecified urinary organ cancer & $0.87(0.44-1.72)$ & 0.6887 & $0.44(0.10-1.92)$ & 0.2765 & $1.14(0.52-2.51)$ & 0.7390 \\
\hline Thyroid cancer & $1.71(1.22-2.41)$ & 0.0021 & $0.86(0.25-2.98)$ & 0.8085 & $1.84(1.28-2.63)$ & 0.0009 \\
\hline Hodgkin's lymphoma & $1.77(1.13,2.79)$ & 0.0134 & $3.00(1.04-8.65)$ & 0.0419 & $0.67(0.08-5.54)$ & 0.7074 \\
\hline Non-Hodgkin's lymphoma & $2.00(0.81-4.96)$ & 0.1342 & $1.29(0.63-2.63)$ & 0.4827 & $2.27(1.25-4.12)$ & 0.0070 \\
\hline
\end{tabular}

Table 3. Odd ratio of specific cancers in patients with keloids, stratified by gender. OR odd ratio, 95\% CI 95\% confidence interval.

ney cancer $(\mathrm{OR}=1.77)$, thyroid cancer $(\mathrm{OR}=1.71)$, and Hodgkin's lymphoma $(\mathrm{OR}=1.77)$. Additionally, female patients with keloids were associated with non-Hodgkin's lymphoma $(\mathrm{OR}=2.27)$, as well.

Adjusted RR of specific cancers in patients with keloids (Table 4). We then focused on the specific cancers that showed increases in OR. A cohort study was then performed to evaluate the association between keloids and specific cancer types. From January 1, 1998 to December 31, 2010, in patients who had been diagnosed with specific cancer types before their diagnosis of keloids, temporality was corrected, and the patients were excluded. The results showed that keloids patients had increased risk of skin cancer $(\mathrm{RR}=1.73,95 \% \mathrm{CI}$ 1.13-2.63). Surprisingly, however, keloids patients had lower risks of colon cancer (RR $=0.66,95 \%$ CI $0.51-0.86)$ and liver cancer $(\mathrm{RR}=0.73,95 \% \mathrm{CI} 0.56-0.96)$. Further gender-stratified analysis revealed that male patients with keloids were vulnerable to skin cancer $(\mathrm{RR}=2.16,95 \% \mathrm{CI} 1.17-4.00)$ but protected from prostate cancer $(\mathrm{RR}=0.48,95 \%$ CI $0.28-0.83)$ or colon cancer $(\mathrm{RR}=0.66,95 \%$ CI $0.45-0.96)$. Female patients with keloids were vulnerable to pancreatic cancer $(R R=2.39, \mathrm{P}=0.0293)$ but protected from breast cancer $(\mathrm{RR}=0.55,95 \%$ $\mathrm{CI}=0.43-0.78)$, colon cancer $(\mathrm{RR}=0.66,95 \% \mathrm{CI} 0.47-0.94)$ or liver cancer $(\mathrm{RR}=0.67,95 \% \mathrm{CI} 10.46-0.99)$. Besides, female patients with keloids had an increased risk of skin cancer although this risk does not reach statistical significance.

Keloids were an independent risk factor for pancreatic cancer in females. The incidence of skin cancers was consistently higher in patients with keloids compared to controls. Female patients with keloids had an increased risk of pancreatic cancer $(R R=2.19,95 \%$ CI 1.08-4.42). Previous studies have found that chronic pancreatitis, liver cirrhosis, and diabetes mellitus are important risk factors for pancreatic cancer ${ }^{10,11}$. Therefore, RRs were calculated after adjustment for these covariates and stratification by these comorbidities (Table 5). While chronic pancreatitis was the most important risk factor for pancreatic cancer $(\mathrm{RR}=16.71)$, the keloids group still had a higher risk of developing pancreatic cancer compared to controls $(\mathrm{RR}=2.05)$. Next, Cox proportional hazard regression analysis was used to investigate the interacting effects of chronic pancreatitis and keloids on the development of pancreatic cancers. Table 6 shows that chronic pancreatitis and keloids did not have a statistically significant interacting effect ( $\mathrm{p}$ for interaction 0.5695 ). The data indicated that keloids and chronic pancreatitis were both independent risk factors and joint risk factors for pancreatic cancers.

\section{Discussion}

To the best of our knowledge, this study is the first to demonstrate an association between keloids and human cancers in an Asian population. The main findings of the study support our hypothesis that keloids patients have a higher than normal risk of developing cancers, especially skin cancer and pancreatic cancer. Overall cancer risk was 1.49-fold higher in the keloids group compared to the control group. Notably, the cancer risk in keloids 


\begin{tabular}{|c|c|c|c|c|c|c|c|c|c|c|c|c|}
\hline \multirow{2}{*}{$\begin{array}{l}\text { Variables } \\
\text { Cancer }\end{array}$} & \multicolumn{4}{|l|}{ All } & \multicolumn{4}{|l|}{ Males } & \multicolumn{4}{|l|}{ Females } \\
\hline & $\begin{array}{l}\text { Crude RR } \\
(95 \% \text { CI })\end{array}$ & $P$ value & $\begin{array}{l}\text { Adjusted } \mathrm{RR}^{\mathrm{a}} \\
(95 \% \mathrm{CI})\end{array}$ & $P$ value & $\begin{array}{l}\text { Crude RR } \\
(95 \% \text { CI })\end{array}$ & P value & $\begin{array}{l}\text { Adjusted RR }{ }^{\mathrm{a}} \\
(95 \% \mathrm{CI})\end{array}$ & P value & $\begin{array}{l}\text { Crude RR } \\
\text { (95\% CI) }\end{array}$ & $P$ value & $\begin{array}{l}\text { Adjusted } \mathrm{RR}^{\mathrm{a}} \\
(95 \% \mathrm{CI})\end{array}$ & P value \\
\hline $\begin{array}{l}\text { Esophageal } \\
\text { cancer }\end{array}$ & $\begin{array}{l}0.68 \\
(0.35-1.33)\end{array}$ & 0.2575 & $\begin{array}{l}0.67 \\
(0.34-1.30)\end{array}$ & 0.2337 & & & & & & & & \\
\hline Colon cancer & $\begin{array}{l}0.68 \\
(0.53-0.88)\end{array}$ & 0.0031 & $\begin{array}{l}0.66 \\
(0.51-0.86)\end{array}$ & 0.0016 & \begin{tabular}{|l|}
0.71 \\
$(0.48-1.03)$
\end{tabular} & 0.0728 & \begin{tabular}{|l|}
0.66 \\
$(0.45-0.96)$
\end{tabular} & 0.0316 & $\begin{array}{l}0.66 \\
(0.47-0.93)\end{array}$ & 0.0184 & $\begin{array}{l}0.66 \\
(0.47-0.94)\end{array}$ & 0.0196 \\
\hline Liver cancer & $\begin{array}{l}0.74 \\
(0.57-0.98)\end{array}$ & 0.0327 & $\begin{array}{l}0.73 \\
(0.56-0.96)\end{array}$ & 0.0251 & $\begin{array}{l}0.83 \\
(0.56-1.22)\end{array}$ & 0.3491 & $\begin{array}{l}0.80 \\
(0.54-1.17)\end{array}$ & 0.2527 & $\begin{array}{l}0.67 \\
(0.45-0.98)\end{array}$ & 0.0416 & $\begin{array}{l}0.67 \\
(0.46-0.99)\end{array}$ & 0.0440 \\
\hline $\begin{array}{l}\text { Pancreatic } \\
\text { cancer }\end{array}$ & $\begin{array}{l}1.72 \\
(0.99-2.98)\end{array}$ & 0.0555 & $\begin{array}{l}1.66 \\
(0.95-2.88)\end{array}$ & 0.0730 & $\begin{array}{l}1.20 \\
(0.48-2.99)\end{array}$ & 0.6940 & $\begin{array}{l}1.11 \\
(0.44-2.76)\end{array}$ & 0.8295 & $\begin{array}{l}.18 \\
(1.08-4.41)\end{array}$ & 0.0296 & $\begin{array}{l}2.19 \\
(1.08-4.42)\end{array}$ & 0.0293 \\
\hline Melanoma & $\begin{array}{l}1.40 \\
(0.59-3.31)\end{array}$ & 0.4424 & $\begin{array}{l}1.39 \\
(0.59-3.29)\end{array}$ & 0.4554 & $\begin{array}{l}1.60 \\
(0.50-5.10)\end{array}$ & 0.4263 & $\begin{array}{l}1.47 \\
(0.46-4.71)\end{array}$ & 0.5130 & $\begin{array}{l}1.20 \\
(0.33-4.36)\end{array}$ & 0.7811 & $\begin{array}{l}1.25 \\
(0.34-4.55)\end{array}$ & 0.7338 \\
\hline Skin cancer & $\begin{array}{l}1.73 \\
(1.13-2.63)\end{array}$ & 0.0110 & $\begin{array}{l}1.73 \\
(1.13-2.63)\end{array}$ & 0.0112 & $\begin{array}{l}2.29 \\
(1.24-4.24)\end{array}$ & 0.0081 & $\begin{array}{l}2.16 \\
(1.17-4.00)\end{array}$ & 0.0139 & $\begin{array}{l}1.37 \\
(0.76-2.46)\end{array}$ & 0.2961 & $\begin{array}{l}1.43 \\
(0.79-2.57)\end{array}$ & 0.2329 \\
\hline Breast cancer & & & & & & & & & $\begin{array}{l}0.58 \\
(0.43-0.78)\end{array}$ & 0.0003 & $\begin{array}{l}0.58 \\
(0.43-0.78)\end{array}$ & 0.0003 \\
\hline Prostate cancer & & & & & $\begin{array}{l}0.57 \\
(0.33-0.98)\end{array}$ & 0.0406 & $\begin{array}{l}0.48 \\
(0.28-0.83)\end{array}$ & 0.0083 & & & & \\
\hline Kidney cancer & $\begin{array}{l}0.65 \\
(0.29-1.45)\end{array}$ & 0.2933 & $\begin{array}{l}0.66 \\
(0.30-1.47)\end{array}$ & 0.3116 & & & & & & & & \\
\hline Thyroid cancer & $\begin{array}{l}0.76 \\
(0.48-1.22)\end{array}$ & 0.2604 & $\begin{array}{l}0.77 \\
(0.48-1.23)\end{array}$ & 0.2690 & & & & & $\begin{array}{l}0.79 \\
(0.49-1.3)\end{array}$ & 0.3571 & $0.79(0.49-1.3)$ & 0.3591 \\
\hline $\begin{array}{l}\text { Hodgkin's } \\
\text { lymphoma }\end{array}$ & & & & & $\begin{array}{l}0.50 \\
(0.06-4.00)\end{array}$ & 0.5139 & $\begin{array}{l}0.51 \\
(0.06-4.07)\end{array}$ & 0.5242 & & & & \\
\hline $\begin{array}{l}\text { Non-Hodgkin's } \\
\text { lymphoma }\end{array}$ & $\begin{array}{l}0.92 \\
(0.51-1.64)\end{array}$ & 0.7748 & $\begin{array}{l}0.92 \\
(0.51-1.64)\end{array}$ & 0.7781 & & & & & $\begin{array}{l}1.47 \\
(0.74-2.93)\end{array}$ & 0.2759 & $\begin{array}{l}1.48 \\
(0.74-2.95)\end{array}$ & 0.2662 \\
\hline
\end{tabular}

Table 4. Relative risk of specific cancers in patients with keloids, stratified by gender. $R R$ relative risk, $95 \%$ CI 95\% confidence interval. ${ }^{a}$ Model adjusted for age group, gender, and the residential region using a Cox proportional-hazards regression model.

\begin{tabular}{|c|c|c|c|c|c|c|}
\hline Variables & $\mathbf{N}$ & Pancreatic cancer & Crude RR (95\% CI) & P-value & Adjusted RR ${ }^{a}(95 \%$ CI $)$ & P-value \\
\hline Non-keloids group & 43,064 & 22 & 1.00 & & 1.00 & \\
\hline Keloids & 10,762 & 12 & $2.18(1.08-4.41)$ & 0.0296 & $2.05(1.01-4.17)$ & 0.0459 \\
\hline \multicolumn{7}{|l|}{ Liver cirrhosis } \\
\hline No & 53,488 & 33 & 1.00 & & 1.00 & \\
\hline Yes & 338 & 1 & $4.80(0.66-35.06)$ & 0.1224 & $1.53(0.2-11.5)$ & 0.6772 \\
\hline \multicolumn{7}{|l|}{ Chronic pancreatitis } \\
\hline No & 53,707 & 31 & 1.00 & & 1.00 & \\
\hline Yes & 119 & 3 & $43.68(13.35-142.86)$ & $<0.0001$ & $16.71(4.91-56.87)$ & $<0.0001$ \\
\hline \multicolumn{7}{|l|}{ Diabetes mellitus } \\
\hline No & 48,539 & 24 & 1.00 & & 1.00 & \\
\hline Yes & 5287 & 10 & $3.83(1.83-8.00)$ & 0.0004 & $1.22(0.54-2.73)$ & 0.6362 \\
\hline
\end{tabular}

Table 5. Pancreatic cancer risk in female patients with keloids, stratified by comorbidities. $R R$ relative risk, 95\% CI 95\%confidence interval. ${ }^{a}$ Model adjusted for age group, gender, the residential region and related comorbidities using a Cox proportional-hazards regression model.

patients was increased regardless of gender. The relationship between cancers and keloids varied by cancer type. Keloids patients had a 1.73-fold higher risk of developing skin cancer compared to non-keloids patients, and male patients with keloids had an even higher RR (2.16).

The underlying mechanisms of the association between keloids and human cancers remain to be determined. However, several lines of evidence from previous studies indicate that keloids and human cancers may share similar pathophysiological processes. Firstly, prolonged inflammation with elevated proinflammatory cytokines in injured tissues contributes to keloidogenesis ${ }^{12-18}$. Chronic inflammation is known to promote tumor development and progression in skin cancers, melanoma and pancreatic cancers ${ }^{19}$. For example, studies have shown that nuclear factor-kappa B, activator and signal transducer of transcription 3, hypoxia-inducible factor- 1 alpha cytokines and chemokines play critical role of inflammation in the carcinogenesis of skin cancer and pancreatic cancer ${ }^{19,20}$. Interestingly, patients with chronic pancreatitis are known to have a high risk of developing pancreatic cancer, which suggests that chronic inflammatory processes may be the master mediators of pancreatic cancer ${ }^{21}$. In short, chronic inflammation is likely to result in fibrosis that may mediate the development of both keloids and cancers. 


\begin{tabular}{|l|l|l|l|l|l|l|l|l|}
\hline Variables & & $\mathbf{N}$ & $\begin{array}{l}\text { Pancreatic } \\
\text { cancer }\end{array}$ & $\begin{array}{l}\text { Crude RR (95\% } \\
\text { CI) }\end{array}$ & P-value & $\begin{array}{l}\text { Adjusted RR } \\
(\mathbf{9 5 \%} \text { CI) }\end{array}$ & P-value $^{\mathbf{a}}$ & $\begin{array}{l}\mathbf{P}_{\text {for }} \\
\text { interaction }\end{array}$ \\
\hline Keloids & $\begin{array}{l}\text { Chronic pan- } \\
\text { creatitis }\end{array}$ & & & & & & \\
\hline No & No & 42,979 & 20 & Reference & & Reference & \\
\hline Yes & No & 10,728 & 11 & $2.20(1.06-4.60)$ & 0.0353 & $2.20(1.05-4.60)$ & 0.0355 \\
\hline No & Yes & 85 & 2 & $\begin{array}{l}50.56(11.82- \\
216.33)\end{array}$ & $<0.0001$ & $\begin{array}{l}22.34(5.06- \\
98.65)\end{array}$ & $<0.0001$ \\
\hline Yes & Yes & 34 & 1 & $\begin{array}{l}63.22(8.49- \\
470.95)\end{array}$ & $<0.0001$ & $\begin{array}{l}23.67(3.10- \\
180.78)\end{array}$ & 0.0023 \\
\hline
\end{tabular}

Table 6. Interacting effects of keloids and chronic pancreatitis on the development of pancreatic cancer in female patients with keloids. $R R$ relative risk, $C I$ confidence interval. a Model adjusted for age group, gender, and the residential region, liver cirrhosis and diabetes mellitus using a Cox proportional-hazards regression model. ${ }^{b}$ Interactions between keloid cases and chronic pancreatitis were calculated using the Cox proportional hazards regression model with an added interaction term for keloid cases by chronic pancreatitis and covariates.

Secondly, TGF- $\beta 1$ has emerged as a potent growth factor in wound healing and inflammation. The TGF- $\beta 1$ regulates cell growth and differentiation as well as cancer initiation and progression. Many studies have reported that elevated TGF- $\beta 1$ in keloidal tissue stimulates dermal fibroblast proliferation and differentiation as well as collagen formation ${ }^{22}$. The TGF- $\beta$ regulates phosphorylation of Smad family proteins ${ }^{23}$. Wu el al. reported that TGF- $\beta 1$ increases phosphorylation of Smad2/3 and Smad4 in keloidal fibroblasts ${ }^{24}$. Jialiang el al., which was the first study to demonstrate increased Smad4 expression and decreased Smad7 expression in keloids, proposed that Toll-like receptors (TLRs) exert contribute to keloidogenesis through TGF- $\beta /$ Smad signaling ${ }^{25}$. Subsequent studies have confirmed the critical role of TGF- $\beta /$ Smad signaling in keloidogenesis ${ }^{26-31}$. Similarly, TGF- $\beta /$ Smad signaling reportedly has roles in the development of skin cancers and pancreatic cancer ${ }^{32}$. The TGF- $\beta 1$ secreted from pancreatic damaged acinar cells and cancer cells is a fibrotic growth or pro-tumorigenic factor ${ }^{33,34}$. Therefore, TGF- $\beta$ /Smad signaling has a pivotal role in the pathogenesis of keloids and cancers.

Finally, micro-RNAs (miRNAs) can contribute to cancer development. This group of conserved, non-coding, and single-stranded small RNA molecules of 21-25 nucleotides control gene expressions and are important for maintaining cellular hemostasis ${ }^{35,36}$. Specific miRNA dysregulation has profound impacts on cellular physiological changes that have been associated with various diseases ${ }^{37}$. The pleiotropic role of miRNAs in metastasis, fibrotic processes, and genesis of cancer is well-documented ${ }^{38-41}$. Reduced expression of some miRNAs, e.g., miR29 , has been associated with keloids development ${ }^{42-46}$. Similarly, cancer cells often exhibit reduced expression of miR-29 family members that have important roles in the tumor microenvironment and cancer pathogenesis ${ }^{47,48}$. For example, Schmitt et al. reported that patients with metastatic melanoma had low expressions of miR-29a and miR-29b ${ }^{49}$, and Kwon et al. showed that decreased miR-29 in activated pancreatic stellate cells correlated with increased extracellular matrix ${ }^{50}$.

The incidence of pancreatic cancer is low, but it increases at a rate of $1.4-1.8 \%$ per year of age. The dismal 5 -year survival rate (8\%) results in high mortality ${ }^{51}$. Only two studies have reported an association between pancreatic tumors and keloids. Speer et al. analyzed a 20-year (1991-2011) series of pediatric patients treated for solid pseudopapillary tumor of the pancreas at a single institution. The authors reported that these patients had a high incidence of developing incisional keloids after abdominal surgery ${ }^{52}$. Pasquali et al. reported that only one patient developed keloids out of 109 patients who had undergone surgery for neuroendocrine pancreatic tumors during 1980-2001 ${ }^{53}$. However, the association between pancreatic cancer and keloids requires further study. As mentioned above, the link between pancreatic cancer and keloids may be attributable to chronic inflammation and TGF- $\beta /$ Smad signaling. The Akt is activated in both skin cancers and pancreatic cancers ${ }^{54,55}$. Clinical evidence also indicates that miR-21 and miR-29 share a common pathophysiology in the development of keloids and pancreatic cancers. Furthermore, YAP (yes-associated protein) and TAZ (transcriptional coactivator with PDZ-binding motif) are part of a classic pathway that controls the contact inhibition in the Hippo signaling pathway. They also have a similar role in the pathophysiology of keloids and pancreatic cancer development, i.e., modulation of pancreatic tissue regeneration, neoplastic transformation, and stellate cell function ${ }^{56}$.

The major strength in this study is the use of a database from a nationwide, single-payer health care system. The large sample size provided sufficient statistical power for comparisons. Moreover, since data were obtained from a nationwide registry rather than from a hospital-based registry, the calculation of cancer incidences was accurate. Another strength of this study is that the data were derived from the Taiwan nationwide healthcare system, in which most participants are Asians. Therefore, analysis of this population yields important insights into the roles of genetic ancestry in keloids and cancers.

Some limitations of this study are noted. First, for better ICD code accuracy, the occurrence of keloid was defined as diagnoses made by a dermatologist or a plastic surgeon in this study. The specificity of keloid diagnosis in this manner is high, however, the actual incidence of keloids may be underestimated. Second, the database did not provide information that could be used to determine how the severity, extent, or location of keloids affects cancer risk. Third, the database did not provide information about genetic and environmental factors that can have important roles in keloids pathogenesis as well as cancer formation; such factors include body mass index, lifestyle, social habits, family history, and laboratory examination data. Fourth, most participants were ethnic 


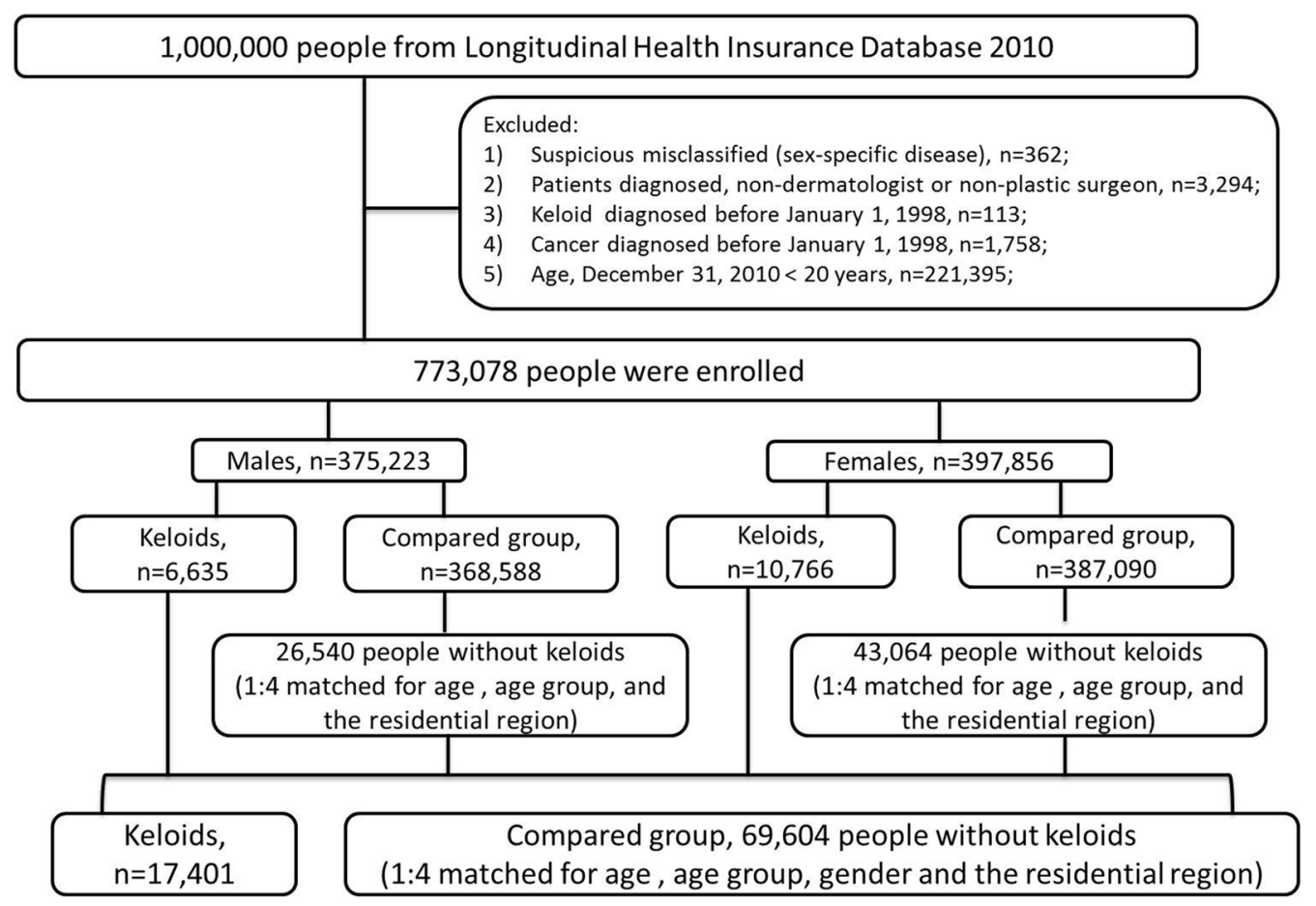

Figure 1. Workflow of the diagnostic process for keloids and cancers using the Longitudinal Health Insurance Database 2010.

Chinese, which limits the ability to generalize the results to other racial populations. Finally, although statistically significant, further mechanistic studies are warranted to understand the pathomechanisms.

\section{Conclusions}

In summary, the association between human cancers and keloids is organ specific. This study is the first to analyze cancer risk, specifically, pancreatic cancer risk in females and skin cancer risk in both genders, in an Asian population of patients with keloids. The results of this study indicate that, regardless of gender, patients with keloids should routinely undergo skin examination to ensure early identification of skin cancers. Additionally, female patients with keloids should undergo scheduled physical and laboratory follow-up examinations, e.g., abdominal ultrasonography and blood tumor marker test, to screen for pancreatic cancer.

\section{Materials and methods}

Data source. The NHIRD, one of the largest nationwide population-based databases, was established by the National Health Research Institutes in Taiwan. This encrypted secondary database implemented in March 1995, contains data for Taiwan residents covered by single-payer government insurance, which currently includes $99 \%$ of all Taiwan residents. The original medical claims data contained in the NHIRD are available to researchers and have been used extensively for epidemiological studies in Taiwan ${ }^{57}$. Data retrieved from the NHIRD was deidentified and encrypted. In accordance with Personal Electronic Data Protection Law, individual information which can be utilized to identify beneficiaries and hospitals must be removed from the NHIRD. All data from the NHIRD were anonymized to protect the participants' privacy. This study used the NHIRD Longitudinal Health Insurance Database (LHID) 2010, which contains data for a nationally representative random sample of 1 million insurance beneficiaries who enrolled in the NHIRD in 2010.

Study design. All diagnoses in the analysis were coded according to the International Classification of Diseases, Ninth Revision, Clinical Modification (ICD-9-CM). First, 17,401 patients with keloids (ICD-9-CM code 701.4) were identified in the LHID ${ }^{58,59}$. A comparison group of 69,604 patients without keloids were then matched at a ratio of 1:4 for age, age group, gender, and region of residence by propensity scores.

Figure 1 shows the workflow of the study population. This is a population-based observational study with a cross-sectional and a retrospective cohort study design to elucidate the association between keloid and cancer. At first using a cross sectional design in the database of LHID2010, all patients with a record of a first-time diagnosis of keloids by a dermatologist or a plastic surgeon from January 1, 1998 to December 31, 2010 were eligible for inclusion in this study. When subjects with keloids were categorized by many different type of cancers, numbers of the subjects in each category (by cancer types) could be too low to distort the actual prevalence. Therefore, in this first part of cross-sectional study, a logistic regression was performed to explore the association of keloid with overall incident cancer and different kind of cancers. 
After the association of ALL cancers with keloids were successfully established by the logistic regression, a retrospective cohort study was performed to evaluate the risk of the development of specific cancers in patients with keloid. To overcome the initially overlooked odd risks by using logistic regression, in patients who had a specific cancer diagnosis before a keloid diagnosis (the index date of keloid onset), temporality was corrected, and these patients were excluded. Relative risk of specific cancer was determined by Cox proportional hazard regression modeling after adjusting common covariates (age, gender and the residential region).

Ethical approval. The study was performed according to Declaration of Helsinki guidelines and was approved by the Institutional Review Board of Chang Gung Medical Foundation. (IRB No. 201801614B1). According to the regulations of Institutional Review Board of Chang Gung Medical Foundation, the need for informed consent was waived per protocol.

Measurement and definition. The occurrence of keloids was defined as $\geq 2$ keloid diagnosis (ICD-9-CM code 701.4) in outpatient visits or inpatient visits. The index date of keloids onset was defined as the earliest date of a keloid diagnosis. Patients were excluded if they were younger than 20 years at the time of keloid diagnosis in 2010 in accordance to IRB regulations.

The primary outcome was overall incident cancer, including all the specific cancers as below. The secondary outcomes were different specific cancers: oral cancer (ICD-9-CM code 140-149), esophageal cancer (ICD-9-CM code 150), stomach cancer (ICD-9-CM code 151), colon cancer (ICD-9-CM code 153), liver cancer (ICD-9-CM code 155), pancreatic cancer (ICD-9-CM code 157), lung cancer (ICD-9-CM code 162), melanoma (ICD-9-CM code 172), skin cancers (ICD-9-CM code 173), female breast cancer (ICD-9-CM code 174), male breast cancer (ICD-9-CM code 175), Kaposi's sarcoma (ICD-9-CM code 176), cervical cancer (ICD-9-CM code 180), uterine cancer (ICD-9-CM code 182), ovarian cancer (ICD-9-CM code 183), prostate cancer (ICD-9-CM code 185), bladder cancer (ICD-9-CM code 188), kidney cancer (ICD-9-CM code 189.0), unspecified urinary organ cancer (ICD-9-CM code 189 excluding 189.0), thyroid cancer (ICD-9-CM code 193), Hodgkin's lymphoma (ICD-9-CM code 201) and non-Hodgkin's lymphoma (ICD-9-CM code 202). A cancer was defined as $\geq 2$ diagnosis in outpatient visits or inpatient visits. Comorbidities included diabetes mellitus (ICD-9-CM code 250), liver cirrhosis (ICD-9-CM code 571.5) and chronic pancreatitis (ICD-9-CM code 577.1).

Statistical analyses. Categorical variables were presented as numbers and percentages while continuous variables were reported as means \pm standard deviations (SDs). Categorical variables were compared with Chisquare test, and continuous variables were compared with Student's t test, as appropriate. We first used logistic regression to explore the association of keloid with different kind of cancers. In order to increase the sensitivity to detect this association, the timely association were initially overlooked. After the association of ALL cancers with keloids were successfully established by logistic regression, a cohort study was performed to evaluate the risk of the development of specific cancers in patients with keloid from January 1, 1998 to December 31, 2010. In patients who had a specific cancer diagnosis before a keloid diagnosis, temporality was corrected, and the patients were excluded. Relative risk (RR) of cancer was determined by Cox proportional hazard regression modeling after adjusting common covariates (age, gender and the residential region). In pancreatic cancer, adjusted RR was assessed after adjusting not only above covariates but also reported comorbidities including diabetes mellitus, liver cirrhosis and chronic pancreatitis ${ }^{10,11}$. A two-tailed p-value $<0.05$ was considered statistically significant for all analyses. Statistical analyses were performed using SAS version 9.4 (SAS Institute, Cary, NC, USA).

Received: 25 December 2020; Accepted: 15 April 2021

Published online: 30 April 2021

\section{References}

1. Murray, J. C., Pollack, S. V. \& Pinnell, S. R. Keloids: A review. J. Am. Acad. Dermatol. 4, 461-470 (1981).

2. Gauglitz, G. G. Management of keloids and hypertrophic scars: Current and emerging options. Clin. Cosmet. Investig. Dermatol. 6, 103-114 (2013).

3. Halim, A. S., Emami, A., Salahshourifar, I. \& Kannan, T. P. Keloid scarring: Understanding the genetic basis, advances, and prospects. Arch. Plast. Surg 39, 184-189 (2012).

4. Gauglitz, G. G., Korting, H. C., Pavicic, T., Ruzicka, T. \& Jeschke, M. G. Hypertrophic scarring and keloids: Pathomechanisms and current and emerging treatment strategies. Mol. Med. 17, 113-125 (2011).

5. Al-Attar, A., Mess, S., Thomassen, J. M., Kauffman, C. L. \& Davison, S. P. Keloid pathogenesis and treatment. Plast. Reconstr. Surg. 117, 286-300 (2006).

6. Viera, M. H., Caperton, C. V. \& Berman, B. Advances in the treatment of keloids. J. Drugs Dermatol. 10, 468-480 (2011).

7. He, Y., Merin, M. R., Sharon, V. R. \& Maverakis, E. Eruptive keloids associated with breast cancer: A paraneoplastic phenomenon?. Acta Derm. Venereol. 91, 480-481 (2011).

8. Sakaguchi, M. et al. Bilateral breast keloids in an elderly woman associated with bilateral breast cancers and high concentration of serum tumor growth factor-beta. J. Dermatol. 44, 1303-1308 (2017).

9. Coppa, L. M., Alam, M., Longley, B. J. \& Stiller, M. J. Eruptive paraneoplastic keloids. Cutis 64, 243-244 (1999).

10. Del Chiaro, M., Segersvard, R., Lohr, M. \& Verbeke, C. Early detection and prevention of pancreatic cancer: Is it really possible today?. World J. Gastroenterol. 20, 12118-12131 (2014).

11. Becker, A. E., Hernandez, Y. G., Frucht, H. \& Lucas, A. L. Pancreatic ductal adenocarcinoma: Risk factors, screening, and early detection. World J. Gastroenterol. 20,11182-11198 (2014).

12. Ogawa, R. Keloid and hypertrophic scars are the result of chronic inflammation in the reticular dermis. Int. J. Mol. Sci. 18, 606 (2017).

13. Shi, C., Zhu, J. \& Yang, D. The pivotal role of inflammation in scar/keloid formation after acne. Dermatoendocrinology 9 , e1448327 (2017). 
14. Chen, W. et al. Analysis of differentially expressed genes in keloids and normal skin with cDNA microarray. J. Surg. Res. 113, 208-216 (2003).

15. Dong, X., Mao, S. \& Wen, H. Upregulation of proinflammatory genes in skin lesions may be the cause of keloid formation (Review). Biomed. Rep. 1, 833-836 (2013).

16. Maung, A. A. et al. Enhanced TLR4 reactivity following injury is mediated by increased p38 activation. J. Leukoc. Biol. 78, 565-573 (2005).

17. Murphy, T. J., Ni Choileain, N., Zang, Y., Mannick, J. A. \& Lederer, J. A. CD4+CD25+ regulatory T cells control innate immune reactivity after injury. J. Immunol. 174, 2957-2963 (2005).

18. Drummond, P. D., Dawson, L. F., Wood, F. M. \& Fear, M. W. Up-regulation of alpha1-adrenoceptors in burn and keloid scars. Burns 44, 582-588 (2018).

19. Maru, G. B., Gandhi, K., Ramchandani, A. \& Kumar, G. The role of inflammation in skin cancer. Adv. Exp. Med. Biol. 816, 437-469 (2014).

20. Zambirinis, C. P., Pushalkar, S., Saxena, D. \& Miller, G. Pancreatic cancer, inflammation, and microbiome. Cancer J. 20, 195-202 (2014).

21. Hausmann, S., Kong, B., Michalski, C., Erkan, M. \& Friess, H. The role of inflammation in pancreatic cancer. Adv. Exp. Med. Biol. 816, 129-151 (2014).

22. Lee, T. Y. et al. Expression of transforming growth factor beta 1, 2, and 3 proteins in keloids. Ann. Plast. Surg. 43, 179-184 (1999).

23. Liu, T. \& Feng, X. H. Regulation of TGF-beta signalling by protein phosphatases. Biochem. J. 430, 191-198 (2010).

24. Wu, C. S., Wu, P. H., Fang, A. H. \& Lan, C. C. FK506 inhibits the enhancing effects of transforming growth factor (TGF)-beta1 on collagen expression and TGF-beta/Smad signalling in keloid fibroblasts: Implication for new therapeutic approach. Br. J. Dermatol. 167, 532-541 (2012).

25. Chen, J., Zeng, B., Yao, H. \& Xu, J. The effect of TLR4/7 on the TGF-beta-induced Smad signal transduction pathway in human keloid. Burns 39, 465-472 (2013).

26. Chen, Z. et al. Ski diminishes TGF-beta1-induced myofibroblast phenotype via up-regulating Meox2 expression. Exp. Mol. Pathol. 97, 542-549 (2014).

27. Tredget, E. E., Wang, R., Shen, Q., Scott, P. G. \& Ghahary, A. Transforming growth factor-beta mRNA and protein in hypertrophic scar tissues and fibroblasts: Antagonism by IFN-alpha and IFN-gamma in vitro and in vivo. J. Interferon. Cytokine Res. 20, 143-151 (2000).

28. Ghahary, A., Shen, Y. J., Scott, P. G. \& Tredget, E. E. Immunolocalization of TGF-beta 1 in human hypertrophic scar and normal dermal tissues. Cytokine 7, 184-190 (1995).

29. Liu, Y. et al. TGF-beta1 promotes scar fibroblasts proliferation and transdifferentiation via up-regulating MicroRNA-21. Sci. Rep. 6, 32231 (2016).

30. Phan, T. T. et al. Suppression of transforming growth factor beta/smad signaling in keloid-derived fibroblasts by quercetin: Implications for the treatment of excessive scars. J. Trauma 57, 1032-1037 (2004).

31. He, S. et al. Mechanisms of transforming growth factor beta(1)/Smad signalling mediated by mitogen-activated protein kinase pathways in keloid fibroblasts. Br. J. Dermatol. 162, 538-546 (2010).

32. Zhao, M., Mishra, L. \& Deng, C. X. The role of TGF-beta/SMAD4 signaling in cancer. Int. J. Biol. Sci. 14, 111-123 (2018).

33. Apte, M. V. et al. Pancreatic stellate cells are activated by proinflammatory cytokines: Implications for pancreatic fibrogenesis. Gut 44, 534-541 (1999).

34. Bachem, M. G. et al. Pancreatic carcinoma cells induce fibrosis by stimulating proliferation and matrix synthesis of stellate cells. Gastroenterology 128, 907-921 (2005).

35. Ambros, V. microRNAs: Tiny regulators with great potential. Cell 107, 823-826 (2001).

36. Cheng, A. M., Byrom, M. W., Shelton, J. \& Ford, L. P. Antisense inhibition of human miRNAs and indications for an involvement of miRNA in cell growth and apoptosis. Nucleic Acids Res. 33, 1290-1297 (2005).

37. Mendell, J. T. \& Olson, E. N. MicroRNAs in stress signaling and human disease. Cell 148, 1172-1187 (2012).

38. Kota, J. et al. Therapeutic microRNA delivery suppresses tumorigenesis in a murine liver cancer model. Cell 137, 1005-1017 (2009).

39. Esquela-Kerscher, A. et al. The let-7 microRNA reduces tumor growth in mouse models of lung cancer. Cell Cycle 7, 759-764 (2008).

40. Chau, B. N. et al. MicroRNA-21 promotes fibrosis of the kidney by silencing metabolic pathways. Sci. Transl. Med. 4, 121118 (2012).

41. Voller, D., Ott, C. \& Bosserhoff, A. MicroRNAs in malignant melanoma. Clin. Biochem. 46, 909-917 (2013).

42. Liu, Y., Yang, D., Xiao, Z. \& Zhang, M. miRNA expression profiles in keloid tissue and corresponding normal skin tissue. Aesthetic. Plast. Surg. 36, 193-201 (2012).

43. Kashiyama, K. et al. miR-196a downregulation increases the expression of type I and III collagens in keloid fibroblasts. J. Invest. Dermatol. 132, 1597-1604 (2012).

44. Li, C. et al. Comparative study of microRNA profiling in keloid fibroblast and annotation of differential expressed microRNAs. Acta Biochim. Biophys. Sin (Shanghai) 45, 692-699 (2013).

45. Yu, X., Li, Z., Chan, M. T. \& Wu, W. K. microRNA deregulation in keloids: An opportunity for clinical intervention?. Cell Prolif. 48, 626-630 (2015).

46. Wu, Z. Y. et al. Keloid microRNA expression analysis and the influence of miR-199a-5p on the proliferation of keloid fibroblasts. Genet. Mol. Res. 13, 2727-2738 (2014).

47. Jamieson, N. B. et al. MicroRNA molecular profiles associated with diagnosis, clinicopathologic criteria, and overall survival in patients with resectable pancreatic ductal adenocarcinoma. Clin. Cancer Res. 18, 534-545 (2012).

48. Chou, J. et al. GATA3 suppresses metastasis and modulates the tumour microenvironment by regulating microRNA-29b expression. Nat. Cell Biol. 15, 201-213 (2013).

49. Schmitt, M. J. et al. Interferon-gamma-induced activation of Signal Transducer and Activator of Transcription 1 (STAT1) upregulates the tumor suppressing microRNA-29 family in melanoma cells. Cell Commun. Signal 10, 41 (2012).

50. Kwon, J. J. et al. Pathophysiological role of microRNA-29 in pancreatic cancer stroma. Sci. Rep. 5, 11450 (2015).

51. Siegel, R. L., Miller, K. D. \& Jemal, A. Cancer statistics, 2017. CA Cancer J. Clin. 67, 7-30 (2017).

52. Speer, A. L., Barthel, E. R., Patel, M. M. \& Grikscheit, T. C. Solid pseudopapillary tumor of the pancreas: A single-institution 20-year series of pediatric patients. J. Pediatr. Surg. 47, 1217-1222 (2012).

53. Pasquali, C., Sperti, C., Baratella, P., Liessi, G. \& Pedrazzoli, S. Enucleation-resection of pancreatic neuroendocrine tumors: 25 years of experience. Suppl. Tumori. 4, S59-60 (2005).

54. Hafsi, S. et al. Gene alterations in the PI3K/PTEN/AKT pathway as a mechanism of drug-resistance (review). Int. J. Oncol. 40, 639-644 (2012).

55. Shi, Y. et al. Optimal classes of chemotherapeutic agents sensitized by specific small-molecule inhibitors of akt in vitro and in vivo. Neoplasia 7, 992-1000 (2005).

56. Morvaridi, S., Dhall, D., Greene, M. I., Pandol, S. J. \& Wang, Q. Role of YAP and TAZ in pancreatic ductal adenocarcinoma and in stellate cells associated with cancer and chronic pancreatitis. Sci. Rep. 5, 16759 (2015).

57. Wu, C. Y. et al. Osteoporosis in adult patients with atopic dermatitis: A nationwide population-based study. PLoS ONE 12, e0171667 (2017). 
58. Lu, Y. Y. et al. Keloid risk in patients with atopic dermatitis: A nationwide retrospective cohort study in Taiwan. BMJ Open 8, e022865 (2018).

59. Sun, L. M., Wang, K. H. \& Lee, Y. C. Keloid incidence in Asian people and its comorbidity with other fibrosis-related diseases: A nationwide population-based study. Arch Dermatol. Res. 306, 803-808 (2014).

\section{Acknowledgements}

This research work was supported by grants from the Taiwan Ministry of Science and Technology (MOST1072314-B-075B-009; MOST-108-2314-B-075B-001-MY3; MOST-109-2314-B-037-071) and Kaohsiung Veterans General Hospital (VGHKS-104-44; VGHKS-105-57; VGHKS-109-124; KSVGH-110-104). The funders had no role in the study design, data collection and analysis, decision to publish, or preparation of the manuscript.

\section{Author contributions}

Y.Y.L., H.J.Y., K.L.C. and C.H.L. participated in conception and design of the study. H.P.T. performed the data analysis. C.H.W., C.H.H., K.C.Y. and H.J.Y. reviewed the literatures and interpreted the data. Y.Y.L. wrote the manuscript. H.J.Y., K.L.C. and C.H.L. revised the manuscript and supervised the whole study. Y.Y.L. and H.P.T. contributed to obtain fundings. All authors have read and approved the final manuscript.

\section{Competing interests}

The authors declare no competing interests.

\section{Additional information}

Correspondence and requests for materials should be addressed to H.-J.Y., K.-L.C. or C.-H.L.

Reprints and permissions information is available at www.nature.com/reprints.

Publisher's note Springer Nature remains neutral with regard to jurisdictional claims in published maps and institutional affiliations.

(c) (i) Open Access This article is licensed under a Creative Commons Attribution 4.0 International License, which permits use, sharing, adaptation, distribution and reproduction in any medium or format, as long as you give appropriate credit to the original author(s) and the source, provide a link to the Creative Commons licence, and indicate if changes were made. The images or other third party material in this article are included in the article's Creative Commons licence, unless indicated otherwise in a credit line to the material. If material is not included in the article's Creative Commons licence and your intended use is not permitted by statutory regulation or exceeds the permitted use, you will need to obtain permission directly from the copyright holder. To view a copy of this licence, visit http://creativecommons.org/licenses/by/4.0/.

(C) The Author(s) 2021 